\title{
What is Spoken of when We Speak about Being?
}

\author{
Niel Bezrookove
}

June 17, 2020

\begin{abstract}

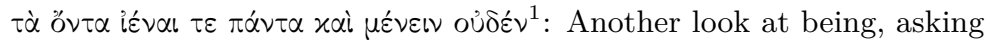
what a interlocutor means to show by saying they feel themselves to be something. An ambiguity of the verb "to be" is disambiguated to reveal that it can be meant to show what something is and a process of being something. The relationship between being and essence is made by describing engagement through the encounter, giving us a non-exhaustive account of something's essence. Practice is then understood as a process within a social context where humans form the senses in which one can be, with their possibilities informed by encounters with what is substantive of those senses. The resulting implications with regards to authenticity, social belonging, and anthropology are briefly discussed.
\end{abstract}

We speak all the time of ourselves being something, and we do so naturally. I must often say that I was being sarcastic. If we gather together to play a sport, someone might say to another "you'll be the goal keeper." In the aftermath of a quarrel, perhaps I would say "I was being insulted." As small talk, I might ask "what's it like being a teacher?" Before a date, someone might say to a nervous person "just be yourself." A particularly curious case- after a mundane

1"All things move and nothing remains still." (Plato \& Reeve, 1998) (Cratylus 401d) 
interaction, a friend of mine remarked that "doing that, I finally felt myself to be Armenian."

This verb 'to be' has its many ambiguities. Of interest is 'to be' as used to show us what is, and to show us what things are. In the examples I previously enumerated, 'to be' is used to show someone existing and subsequently behaving in a particular manner. In the process of living our lives, we find that we must often be many things. We express ourselves with regards to the things we must often be- but what do we mean when we speak of being in this manner?

\section{I.}

It is inevitable that when we speak of being, we touch on that difficult subject of being qua being. My intent here however is not to answer a so-called 'fundamental question of Being qua being,' or what Heidegger refers to as the settling of "a battle of giants concerning being. ${ }^{2}$ " Neither is it to evaluate the structure of being as a word used in the English language, or to ask "what is the logical form of the statement 'I am?'” Rather I hope to orient towards an inquiry into being that begins with the question: "what is meant to be shown when one speaks of being?"

With regards to being qua being, we must keep in mind that there are many categories of what is meant when we speak of being- to quote Aristotle: "there are many senses in which a thing may be said to 'be', but all that 'is' is related to one central point, one definite kind of thing, and is not said to 'be' by a mere ambiguity." Metaphysics describes five senses in which something is, but of particular interest to my inquiry is the distinction between substance, where the essence of a substance is what the thing must be to be itself, and a process to-

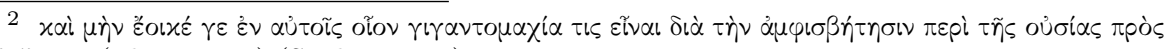
$\alpha \lambda \lambda \dot{n} \lambda$ ous. (Plato, 1921) (Sophist 246a)

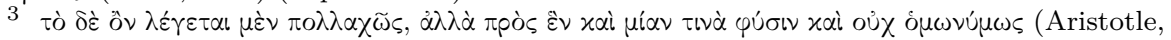
1933) (Metaphysics 1003a)
} 
wards substance. When we describe ourselves as being something, there's never the question that we are at that moment being something other than ourselves, and the person with whom we speak never asks if this description is meant to indicate that we've taken on a different ontological character. Sometimes, we feel that what we are being is in some sense conflicting with what we believe ourselves to be. Therefore, one can say that there is the fact that we are and there is the state of ourselves being something.

I argue that what is spoken of when we speak about us 'being,' stylizing as such to separate it from the rather ambiguous English verb "to be," we mean to show ourselves in a movement towards the essence indicated by the predicate. When my friend remarks that "doing that, I finally felt myself to be Armenian," he means to show that he feels himself moving towards an essence of 'being' Armenian. When I tell you that I'm 'being' sarcastic, I likely mean to show you that you were mistaken about the true nature of what I was being-I'm hinting at the true essence of what I meant. What is of interest here is not the affectation one presents when one hopes to 'be' something. That is a question of what it means to be Armenian or sarcastic. Rather, of interest here is the process of 'being' itself that is undertaken to reveal something about an essence in question that is not simply the essence of what we believe ourselves to be. Whether my friend is Armenian or not is besides the point as the statement "I am being Armenian" is not equivalent to the statement "I am Armenian;" the latter is a statement about one's nationality or ethnic identity but the former refers to a process at hand. The proposition "I am Armenian" is a statement about how things stand, and "I am being Armenian" expresses a belief about the nature of what the interlocutor is doing.

First we must address a basic principle of substance and its essence, that which is necessary in the substance for the substance to 'be' itself. My emphasis 
on what is shown rather than what plainly-spoken is lies contingent on the fact that the essences of substances are not immediate but rather revealed by a process I will call here engagement. Engagement is when an encounter occurs between things, revealing some kind of quality that hints at its essence. In the case of one 'being' Armenian, it would in fact be chauvinistic to claim that the essence of 'being' Armenian is immediate- something one can wholly understand by perception. Rather I suggest here that the essence of 'being' Armenian comes from the process of 'being' Armenian, allowing its "coming to presence ${ }^{4} "$ through engagement.

Engagement happens through the encounter. When we encounter something, we are inevitably put into touch with some essence that is shown by the nature of our engagement. It cannot ever be said that we encounter the essence in its entirety - if you and I engage the same object ${ }^{5}$, we might leave with entirely different encounters, entirely different impressions of its essence even though the object was the same. An encounter leaves with a sense of what we're engaging with, a mode of presentation ${ }^{6}$ that gives us one aspect of what we are encountering. This property of engagement isn't limited to humans, as reactions between two things may also differ- water that engages with mercury reveals different properties compared to water that engages with potassium. Though encounters are not anthropocentric, cognition is necessary for us to say that an encounter leaves one with knowledge of the other's essence. A thing without engagement in relation to anything cannot be said to have properties, whether this is even possible of a thing is a question of ontology. ${ }^{7}$

\footnotetext{
${ }^{4}$ Heidegger, M., \& Lovitt, W. (1977). The question concerning technology, and other essays. Garland Pub.

${ }^{5}$ I distinguish things from objects to make clear a distinction between a discrete physical form we recognize as an object and the greater 'world' of things which includes objects.

${ }^{6}$ Often translated as such but better translated as Art des Gegebenseins, a way of having been, used by Frege in Über Sinn und Bedeutung and perverted here. Can we know every sense of what we encounter? Here I will also quote Frege: "Dahin gelangen wir nie;" we never get there. (Frege \& Voigt, 2019)

${ }^{7}$ To be clear on what is meant by this, even fictional things, concepts, and thoughts have
} 
This encounter is ultimately forced upon us, as engagement is always demanded of us. We cannot make a decision of whether or not our encounter with the thing occurs. It happens when perceive it or conceive of it- if it's there we encounter it. This encounter leaves us irrevocably changed, and doing away with the thing does nothing to change this quality of the encounter. We might remember its existence, and we'll ask "what happened to it?" It might remind us of other memories, it might elicit an emotional response because we're hungry or it has sentimental value to us. We in this sense feel ourselves to 'be' moved by our encounter with this substance, and engagement may very well reveal something about ourselves. Encountering a bear might reveal phobia for such creatures, while engagement with something we are allergic to causes a physical reaction that reveals something about our physical nature. Adopting a role such as teacher or goal keeper may give us the opportunity to learn about ourselves or the social-systems of the world we live in. Engagement here is a continual process of encounters; in this process, a sense of the things involved are always brought to presence but never all at once, and this is true of properties that we hope to show when we speak of 'being.' Therefore, I argue 'being' itself is a continuous process, a roinoıs that brings-forth ${ }^{8}$ and moves us towards an essence rather than a passive property of our existence.

\section{II.}

Now we must address the connection between practice and what we speak of when we speak of 'being' something. Being qua being is the business of all that is but when we speak of 'being' something, we mean that we find ourselves in the condition of practicing what we believe ourselves to 'be.' In Ancient Greek,

properties we engage with. By thing with no properties, I do not mean simply nonexistent things.

${ }^{8}$ Using Heideggerian terminology to stress that this process is revealing what is concealed, a disclosure (Erschlossenheit) 


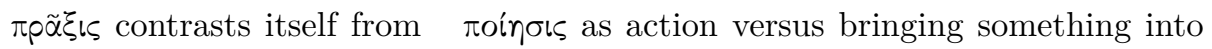
existence-- $\pi$ oin $\sigma \iota \varsigma$ refers to creation and production ${ }^{9}$ while $\pi \rho \tilde{\xi} \xi \varsigma^{10}$ refers to a condition of practicing something. The process of 'being' as roinols is made possible by a practice that allows for engagement with what we believe ourselves to 'be,' as it is within practicing what we believe ourselves to 'be' that we engage with what is substantive of what we are.

Existence itself is not identical to 'being' as we speak of it. Whatever the content or ontological character of existence may be, we should make the point that existence is a necessity that precedes 'being.' In order for something to 'be,' we should accept that it must first exist or else speaking of its 'being' is meaningless. Something is or it's not- if something is, this is shown by virtue of its existence, not its substance. I make this distinction in the hopes of showing why we should speak of practice as a matter of 'being' but not existence. Practice doesn't engage with the fact that we exist, but rather our 'being.' We do not practice existing, as existing is a lemma to the fact that something is, yet we practice 'being.'

When Hamlet asks "to be, or not to be," what he means is really "to exist, or not to exist." However, if Hamlet were to say "to be Hamlet, or not to be Hamlet," I argue he would not be asking a question about existing but a question about what is meant when one says he feels to 'be' Hamlet. One cannot feel like she does not exist as to ask this question is to exist ${ }^{11}$ but one can feel like she is not 'being' herself. To put it succinctly- one by necessity is, but there's the feeling that one must endeavor to 'be.' A dog of course exists, but to speak of it as it needing to endeavor 'being' a dog seems meaningless as the dog does not possess the faculty to 'be' something else nor does it question whether to be

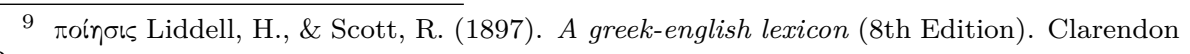
Press

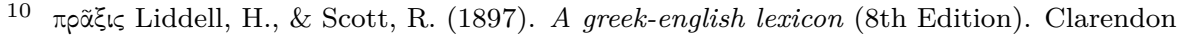
Press

${ }^{11}$ Refer to the Cartesian tautology (e)go sum res cogitans, id est dubitans, affirmans, negans.
} 
itself or not. Likewise objects encounter other objects, and in doing so engage with the properties of other objects, but to speak of water as endeavoring to 'be' water when it reacts with potassium is meaningless. The engagement and its constituent encounters are by no means limited to those with consciousness, but practicing 'being' as far as we know occurs only in homo êns- the human with cognition who therefore knows she not only exists but is. The homo èns is akin to the potter who shapes the natural, indefinite clay of the world into a meaningful and discrete form- a roinoss that gives her a place in which to 'be,' a structure ${ }^{12}$ which gives form in the sense of what is compared to the natural formless of what isn't. Practices enact the potential suggested by the form of the essence of what we are 'being,' as understood through the encounter.

Here our pupil Elisabeth would ask: "but what exactly is meant to be shown by the word 'practice?' Can you point to practice in the world?" Practice is what I call this condition of 'being,' what we are speaking of when we speak of 'being' something. When I'm practicing 'being' a teacher, I am in engagement with spheres ${ }^{13}$ of language, institutions, social roles, and physical space. In the practice of 'being' a teacher, I encounter the essence of what I speak of when I speak of 'being' a teacher even though there are many different senses in which one can 'be' a teacher. It is in this process of practice that I as homo èns learn what it means to 'be' a teacher, and in this practice of 'being' a teacher I show myself moving towards the essence of what is substantive of a teacher while always falling short of knowing its essence in its entirety. Through the practice of 'being' a teacher, I make actual the potentials its essence reveals to us. Therefore the spheres of homo ens are spheres of practice, built by the human who always endeavors to 'be,' encountering the wider world around her

\footnotetext{
${ }^{12}$ These structures are curiously malleable, we can speak of infinitely many senses in which we are 'being' something without confusion about what is meant with its use.

${ }^{13}$ Drawing here from Sloterdijk's description of "the original product of human co-existence," spaces that by being inhabited gain "form, content, extension and relative duration." (Sloterdijk, 2011)
} 
and defining it through her continual practice. To 'be' something is always in the context of a wider world of things which are, shaped by the homo ens who forms her world and establishes what is. ${ }^{14}$ In summation, through encountering the properties of what demands engagement from us, we form senses of the possibilities and potentials ${ }^{15}$ of what is in our world, what we might practice, and through the process of practice we show ourselves to endeavor 'being.'

\section{III.}

Now that we have a clearer understanding of what we speak of when we speak of being, it'll be instructive to address the notion of authenticity. Throughout our lives we endeavor to 'be' many things, but often find ourselves needing to draw a distinction between what we are and what we are 'being.' An example of this would be that one might hear people remark "that's not who I am," or might offer as advice "just be yourself." We intuitively understand that this is not a statement about the essence of the person in question- we do not react by asking how it is possible for you to be anything but yourself at all times. Rather, we show with this utterance that the practice in question is not moving towards what we feel to be the essence of what we are. If I'm being dishonest, but feel myself to be essentially an honest person, I would of course remark "I'm being dishonest but I'm actually an honest person" with which I mean to show that my inauthentic endeavor is purposefully straying from what I believe myself to be.

'Being' here has an informative sense. Something is meant by the statement "I am learning something about myself," which can be stated in more succinct

\footnotetext{
${ }^{14}$ A corollary to the proposition "die Grenzen meiner Sprache bedeuten die Grenzen meiner Welt," or "the limits of my language mean the limits of my world." (Wittgenstein, 1922)

${ }^{15}$ By possibilities and potentials, I mean the causal relations forming the potentiality of what we encounter. Every engagement gives us a sense of possibility as we learn more about the properties of what we encounter. The connection between possibilities, essences, and encounters should be addressed in a later paper.
} 
terms as "I am learning about what I am speaking of when I speak of 'being' myself." In interaction with the authenticity of a practice, our perception allows us to make a connection between the ontic and the ontological. Animals and machines have no concept of ontology, therefore no conception of authenticity as for the animal or the machine there exists perception of the ontic but no question of whether what is perceived is authentic since they possess no conception of 'being. ${ }^{16}$, To speak of a dog acting authentically is meaningless, for the dog has no ontological conception of 'being.' All dogs act authentically, as do machines. However for humans, who have the experience of feeling to 'be' something, a practice is felt to be authentic in relation to what one feels themselves to be.

We must be clear that the purpose of this distinction is not to find a chauvinistic method of separation between the acceptable and unacceptable, to say that some act is authentic and some other act is not. That is not a statement of ontology, but rather one of normative ethics as the injunction made by the utterance of some act being inauthentic and thus unacceptable is that it should not be done. Calling a practice inauthentic is not a pejorative. Performing a role in a play is intentionally acting inauthentic for an artistic purpose. Rather, authenticity here must be understood as a quality ${ }^{17}$ of practice which shows that what is shown by 'being' is not to reveal what we are. One always is, but one can feel that what she is 'being' is not what she is.

Elisabeth could say "well, that person might not feel themselves to be acting authentically but that is because she does not know what she is." We could say that the dog itself is acting authentically or inauthentically but simply does not

\footnotetext{
${ }^{16}$ We should be careful not to find our own anthropocentric projections as proof otherwise, as one can easily ascribe human states to machines and animals. (e.g. "it's being sneaky," "it's being annoying.") There is however the possibility that this is incorrect, and that animals in fact do have a conception of 'being' but one that we can neither recognize nor understand. However, since we cannot evaluate this possibility I prefer the parsimonious option.

${ }^{17}$ I present this quality without moral qualification. The question of inauthenticity's desirability or morality should be disambiguated from its meaning, though they are by no means completely separate.
} 
know when. I feel this to be an undesirable position because it opens us to asking if machines can also act authentically, and an account of authenticity that does not speak strictly of one's own experience of 'being' will undoubtedly devolve into vague cliché. It also makes a categorical error, for 'being' itself is not purely an expression or speech-act made by a person. One might express something as motivated by a feeling of 'being,' but the expression is not identical to what someone is speaking of when they speak of 'being-' no expression can relate fully what we're 'being,' it can only grant a glimpse. Therefore we are incapable of making this distinction of authenticity for the person who speaks of 'being,' as only the person who speaks of 'being' can have the experience of authenticity which relates their feeling of 'being' to the practice. Authenticity described as a quality of 'being' is an internal experience, separate from expressing normative approval of an external act or object as authentic. One intuitively understands for herself when she means to show herself 'being' authentic or not authentic in practice, but this intuition cannot be set outwards onto others or else deceit and lying would be impossible.

We must also avoid certain clichés, which rather than give us a glimpse into this 'being' instead leads us into a rhetorical position. For example, if someone believing themselves to 'be' Armenian were to claim in reference to something happening external to his 'being' that "Armenians who authentically feel themselves to 'be' Armenian don't do that," we are not awarded any light into what it means for that person to 'be' Armenian. Firstly, he might be wrong or mistaken on an empirical level- perhaps Armenians who authentically feel themselves to 'be' Armenian in fact do "that" but this person did not witness them and thus made an error in judgment. Secondly, the distinction drawn lies with the practice in question of "that" even though 'being' Armenian is not a quality of "that" but a quality of a person feeling themselves to 'be' that way. 
A practice has no such inherent quality, there is nothing about it which makes it intrinsically felt to 'be' authentic. Rather it is the people engaging in the practicing who themselves feel to 'be' authentic in performing that practice, which is why someone might say that the authenticity of a performance of said practice is uncertain if people who did not authentically feel themselves to 'be' Armenian performed that practice.

homo èns's creation of spheres of practice always exists within relations of human co-existence, so it cannot be said that the authentic exists within itself purely as an internal experience. Rather authenticity lies between the interaction of 'being' with the practice meant to engage it. We feel ourselves to 'be' authentically, and identify the practice that we've formed within the world with that experience. We cannot assume the authenticity of others, nor can we intuit it, but our spheres of practice hold their proximity to 'being' on the notion of the authentic. Our ideas about what others are 'being' always assumes authenticity, that those spoken of as practicing are always moving towards the essence of what they are 'being. ${ }^{18}$, Therefore the authentic is not something one purely feels about herself in isolation, but something one feels about herself within the relations of human co-existence that form her spheres of practice. There is no private practice, for in practice we show ourselves to 'be,' and the senses of what one can 'be' must be shown by creating these spheres of practice. ${ }^{19}$ To speak of authenticity in a society of one is meaningless, as there would be nothing to show by 'being-' no expression of what I feel myself to 'be' would be necessary and thus none would develop. One exists in private, but it

\footnotetext{
${ }^{18}$ This assumption is what makes deceit and lying possible.

${ }^{19}$ Here one should invoke Wittgenstein's remarks about private languages. In $§ 257$, he writes "Well, let's assume that the child is a genius and invents a name for the sensation by himself! But then, of course, he couldn't make himself understood when he used the word. So does he understand the name, without being able to explain its meaning to anyone? But what does it mean to say that he has 'named his pain'? How has he managed this naming of pain? And whatever he did, what was its purpose? When one says "He gave a name to his sensation", one forgets that much must be prepared in the language for mere naming to make sense." (Wittgenstein \& Anscombe, 1997)
} 
is relation to others that she has a sense of what she's 'being;' without a sense of what one can 'be,' one merely is.

\section{IV.}

When I speak of a sense of what she's 'being' in relation to others, I imply a relationship between 'being' and belonging. If she feels herself to belong to a group, she will inevitably think of how she must 'be' to be Armenian- a common sentiment amongst those who question their identity or sense of belonging. "Am I really Armenian if I don't act Armenian?" What is shown when a Christian believes themselves to 'be' Christian and thus belong? 'Being' itself is not a social relation, but to practice 'being' something one undoubtedly thinks of a social relation as there is no meaning to 'being' Christian if this sense does not show something meaningful. If I speak of 'being' Christian to a community that has no sense of what 'being' Christian means, I'm incapable of showing anything until through practice I show what is meant when I speak of 'being' Christian. This roinols of a sphere of practice gives 'being' Christian its sense, forming a novel possibility of 'being' that can grant us another glimpse at the essence this 'being' orients us towards.

'Being' is not reducible to social relations. It is not sufficient to say that the process of feeling to 'be' Christian occurs through engagement with its symbols and social roles- one cannot ${ }^{20}$ place an arbitrary point at which one is embedded enough within a social structure to begin feeling to'be' Christian. Though an identity of 'Christian' may be imposed on the subject through a social structure, it is from one's own feeling of 'being' with which that social

\footnotetext{
${ }^{20}$ There are many practices with which one reifies this 'being' in the social sphere. In the case of 'being' Christian, a ritual associates a practice with this essence of 'being' Christian. In the case of nationality, a passport and the requisite practice of acquiring it reifies 'being' German. However, this is different from feeling to oneself 'be' German; one should not confuse these reifying practices with the experience of 'being' that one has.
} 
structure is confronted. However the social structure must be there to bring coherence and meaning to that feeling of 'being' Christian, otherwise it would be meaningless to speak of it. A negation of 'being' Christian, "I will not 'be' a Christian," is meaningful only in a social structure where one may feel she knows essence of 'being' Christian and knows other do as well. For a Christian in a social structure that has no conception of Islam to say "I will not 'be' Muslim" purely because she is Christian and therefore not Muslim doesn't reveal anything about what she's 'being' because it is a tautology of definition, akin to $1=1 \therefore 1 \neq 0$. To ask someone to imagine what it feels to not 'be' Christian is a meaningless question, for she could only draw on her experience of 'being' Christian. Likewise, it is impossible to ask someone who doesn't feel themselves to 'be' Christian what it means to 'be' Christian- she might be able to produce an accurate picture of the technology of Christianity, of its books, history, or mythology, but to her the question of what it means to 'be' Christian is an impossible one to answer.

One might intuitively speak of 'being' Armenian as a drawing from an Armenian cultural reserve. When one speaks of belonging or 'being' with regards to a group, they might cite some commonality or generality that binds the group. However, it is difficult to speak of the essence of 'being' Armenian as one can never know this essence in entirety. One can make an account of the cultural reserves, traditions, language, etc. but one cannot speak of a particular practice that makes a 'true' Armenian. Therein lies a question- how can one 'be' Armenian if one doesn't do this specific thing or believe this specific notion from whatever is the symbolic structure? I'd argue we should therefore reject this question as unanswerable, for it would make it impossible or meaningless to 'be' Armenian as one cannot exhaust the meaning of 'being' Armenian or set an arbitrary point of 'being' which would satisfy all Armenians. We often find 
this matter of 'being' creates conflict in our spheres of co-existence, where one is given the legal status of e.g. French but then also expected to 'be' French even though one for herself cannot say to feel as if she's 'being' French simply because she attains a legal status as such-accordingly, in our post-Nationalist world many societies keep these spheres of legal Frenchness and 'being' Frenchness separate for the common good.

Meaning itself is not a physical quality inherent to objects or concepts, rather it occurs in the engagement between that feeling of 'being' and the symbols and social roles as privileged in interpretive anthropology. The sense in which 'Christian' is meaningful comes from the sphere of practice which builds its meaning, but what one means when one says she feels herself to 'be' authentically Christian is a sense one must create for herself. An Armenian friend of mine once remarked "doing that, I finally felt myself to be Armenian." This is not a statement about nationhood or ethnicity but rather an expression of himself finally feeling to 'be' authentically, through a practice that put him in engagement with the possibilities of what 'being' Armenian can mean to him. Each person endeavors to 'be' for themselves, they must encounter the essence for themselves to know in what sense one can authentically 'be-' even if practice is demanded of us before we know the essence of what we are 'being.'

How can one be certain that a person is authentically practicing what they themselves believe to 'be' Christian? The anthropologist cannot avoid this question, for it is the authenticity of its practicing that is of interest in study. ${ }^{21}$ The anthropologist furthers her study with the hopes of transcending the limitations of their own perspective, or otherwise the subject of study would not be the culture of study but rather of the aforementioned perspective in relation to said culture. Though all good scientists understand that they operate within

\footnotetext{
${ }^{21}$ See the controversy surrounding the authenticity of Margaret Mead's study in Samoa that raised questions about how one can be sure she is studying a culture as it is authentically.
} 
the dogmatic prejudices held by the tradition or culture they've been educated in, they do their work with the belief that if said prejudices were removed what remains is an authentic expression that reveals itself.

\section{V.}

In closing I'd like to address 'being' in relationship to anthropology, which distinguishes itself as the study of homo èns's nature unbroken into its constituent atomic parts. Anthropology attempts with its multitude of subfields to enclose the essence of homo èns, to form enough glimpses of its nature so that one may give it an educated definition. In that sense, Aristotle is perhaps the first anthropologist who admitted that to study the human as merely animal would fail to address what separates the human from animals. ${ }^{22}$ If we hold that what separates the human from an animal is her feeling of 'being' something, then those controversies strictly within anthropology should be understood as disagreements on what homo èns reveals to us by its 'being.' Culture itself should be understood as these spheres of practice, continually redefining its possibilities. It falls onto the anthropologist to define the canonical spheres of practice in anthropology - she might say Kochari is a practice of dance canonically Armenian, in contrast to drinking water which is not. Different spheres of practice may inhabit different substrata without overlap, and each are a different encounter of the essence of what the anthropologist takes as her subject of study. The gravity of defining canonical spheres may range from trivial to grave; an anthropologist defining the practices of LGBT peoples as canonically Armenian might have tremendous lasting impacts on the spheres of Armenian social \& political life.

\footnotetext{
${ }^{22}$ Kietzmann, C. (2019). Aristotle on the definition of what it is to be human. In G. Keil \& N. Kreft (Eds.), Aristotle's anthropology (pp. 25-43). Cambridge University Press. https://doi.org/10.1017/9781108131643.002
} 
To speak of essences in anthropology will rightfully garner reluctance \& skepticism. For an anthropologist to speak of a religion's essence places her in a position she wishes not to be, for such an inquiry inevitably drifts into messy questions of personal interpretation that violate the anthropologist's pretence to detached scientific study. ${ }^{23}$ The anthropologist who speaks of her own understanding of a religion's essence will be criticized for drifting into memoir, and routinely dismissed due to the unreliability of her testimony. However, if the anthropologist speaks of interpreting a religion's symbols, history, the beliefs of its adherents as merely forming impressions without certainty of its essenceshe is said to be doing scientific study. The anthropologist cannot speak of humanity's essence, rather she must hold that all these impressions converge to form a lens that will give us a truthful encounter with the essence of homo êns. This is the well from which its meaning is drawn, the revealing of which is the methodology of anthropologists influenced by Geertz' conception of culture. ${ }^{24}$

Without an essence from which an interpretation draws its authority, the anthropologist would find herself doomed to always engage in memoir as the notion of a methodology 'more scientifically sound' would become meaningless; if no symbol is more authoritative than the other, then there is no necessity for the trained anthropologist. Therein lies the difficulty of anthropology. Though the anthropologist cannot speak of this essence, she must perform her work with the premise that it is there as she seeks for the universal in the particular. Anthropology rises from memoir to science when it invokes the particular towards the universal as its own end, as that is where science finds its authority. A science that does not face towards the essence of its subject of study, 'felt' to be closer through abstraction and formalization, has no authority as science as

\footnotetext{
${ }^{23}$ Monks who seek deeper understanding of what they believe to be their religion's essence almost always begin a process of detachment from their wider world.

${ }^{24}$ Geertz, P. (1966). Religion as a cultural system. In M. Banton (Ed.), Anthropological approaches to the study of religion (pp. 1-46). Tavistock
} 
without essence the notion of reproducibility becomes meaningless- without an essence to be reproduced, what is reproduced instead is the memoir. We must either speak of anthropology as an attempt to enclose the essential nature of man and thus 'pin-down' an impression of it, or forfeit that possibility because such essential natures do not exist and anthropology is merely memoir elevated to the authority of science.

\section{VI.}

I hope that by disambiguating the verb "to be," I've made it clear that with "to be" we can make statements with which we show what is and statements with which we show a process of 'being' something. By manner of which I argue that the question of being qua being with regards to ourselves is better addressed by two questions: what are we and what are we being. I gave a definition of the encounter, an act of us engaging with something that allows us for a revealing of that something's concealed essence. Following which I gave a definition of practice, a creative process that creates a manner in which we may endeavour to 'be' and thereby show ourselves engaging with what is substantive of we are 'being.' I then addressed the authentic to address how one might feel to 'be' not herself, and the relationship between 'being' and belonging. Lastly I briefly addressed anthropology, and how a careful definition of 'being' is of some import on its methodology. ${ }^{25}$

Further discussions could address the following:

- Can one speak of herself 'being' something without appealing to the essence substantive of that something? If the first principle from which one applies to 'being' something doesn't arise from an atomic fact, then

\footnotetext{
${ }^{25}$ Gratitude to Jacob Matthews, Sarkis Kassounian, and Elisabeth De Mont for their helpful comments
} 
through what process does one learn what one can denote herself as 'being?'

- Is there the possibility of a thing with no properties in engagement, therefore no essence to encounter? One can adopt either a Meinongian view that such things are merely homeless, obscure until we are given the opportunity to bring them form through thought or a Russellian view that such a statement only appears to be meaningful because of a misunderstanding of descriptions.

- Can anthropology be a rigorous science (such as physics which describes fundamental particles essential to matter) without appeal to a human essence? If so, what is the atomic, or nuclear fact that anthropology attempts to approach if not the question of what is meant when one is 'being' something?

\section{References}

Liddell, H., \& Scott, R. (1897). A greek-english lexicon (8th Edition). Clarendon Press.

Plato. (1921). Sophist (H. N. Fowler, Trans.). Harvard University Press.

Wittgenstein, L. (1922). Tractatus logico-philosophicus. Routledge \& Kegan Paul.

Aristotle. (1933). Metaphysics (H. Tredennick, Trans.). Harvard University Press.

Geertz, P. (1966). Religion as a cultural system. In M. Banton (Ed.), Anthropological approaches to the study of religion (pp. 1-46). Tavistock.

Heidegger, M., \& Lovitt, W. (1977). The question concerning technology, and other essays. Garland Pub. 
Wittgenstein, L., \& Anscombe, G. E. M. (1997). Philosophical investigations. Blackwell.

Plato, \& Reeve, C. (1998). Cratylus. Hackett Publishing Company.

Sloterdijk, P. (2011). Spheres (H. W., Trans.). Semiotext(e).

Frege, G., \& Voigt, U. (2019). Über sinn und bedeutung: [great papers philosophie]. Reclam Philipp Jun.

Kietzmann, C. (2019). Aristotle on the definition of what it is to be human. In G. Keil \& N. Kreft (Eds.), Aristotle's anthropology (pp. 25-43). Cambridge University Press. https://doi.org/10.1017/9781108131643.002 